\title{
The Advantages and Problems of Computer Aided Teaching
}

\author{
Jian Peng \\ Jiangxi Vocational Technical College of Industry \& Trade, Jiangxi, Nanchang,330038 \\ 3107000933@qq.com
}

\begin{abstract}
The application of computer technology in teaching can fully improve the effectiveness of teaching classroom and avoid the possible problems in teaching to a certain extent, so it can also reflect the role of computer technology in teaching, but the application of computer technology in teaching is not only advantages.
\end{abstract}

Keywords: computer aided teaching, advantage, problem

\section{计算机辅助教学的优势与应注意的问题}

\author{
彭健
}

江西工业贸易职业技术学院 南昌 江西 330038

3107000933@qq.com

\section{摘要}

计算机技术在教学中的应用能够使教学课堂的有效性得到充分的提升, 并且能够在一定程度上避免教 育教学课堂中可能出现的问题, 因此也可以体现出计算机技术在教学中的作用, 但是计算机技术在教 学中的应用并不完全只存在优势, 因此本文就主要围绕计算机技术在教学中应用应该注意的问题进行 研究探讨, 同时也阐述了计算机辅助教学的优势。

关键词: 计算机辅助教学; 优势; 问题

\section{1. 计算机辅助教学优势分析}

\section{1. 有助于激发学生兴趣, 促进学生个性发 展}

计算机技术在课堂上的应用能够充分激发学生的 学习兴趣, 因为计算机技术能够使课堂教学变得更加丰 富多彩, 在传统的教育教学课堂中, 教师主要通过板书 来教授学生知识, 而通过计算机技术, 学生能够在教学 课堂上看到和听到更多色彩鲜艳的图片以及影音, 而这 些图片和影音能够使学生集中注意力, 还能使学生对知 识有一个更加清晰的认知, 同时计算机技术还能够催发 学生的求知欲望, 让学生不由自主的对知识进行探索, 而教师如果在教学中应用计算机技术, 就能够为学生营 造一个更加真实的教学情景, 在真实的教学情景下, 学 生的知识水平也能够得到更大幅度的提升。同时计算机 技术还有利于对学生的创新思维进行培养, 因为计算机 技术在教学中的应用不会局限学生的个性发展和思维 发展, 反而能够维护学生的个性发展, 让学生能够充分 发散思维。
1.2. 有助于情境的创设, 激活学生学习积极 性

学生在传统的教育教学模式下, 一直是被动学习的 状态, 而被动学习不利于学生对知识进行深入的了解和 掌握, 因为在被动学习的形态下, 学生对知识没有求知 欲望, 主要依靠教师对学生进行知识的灌输来让学生掌 握知识。但通过这样的方式, 过一段时间之后, 学生就 可能会将这些知识抛掷脑后, 这是因为学生并没有完全 真正的理解知识, 并将这些知识转化为自己的知识, 也 没能够形成自己的知识体系。因此教师在教学中所需要 做的就是引发学生思考, 不但要让学生学习到这些知 识, 还要让学生将这些知识纳入到自己的知识体系中。 而计算机技术就能够帮助教师完成这一教学目的, 因为 计算机技术不受时间和空间的限制, 所以通过计算机辅 助教学就能够更好地促使学生产生学习动机。 


\section{3. 可以更好的针对不同的学生进行教学, 真正的做到因材施教}

学生之间存在不同程度的学习差异, 而学习差异的 产生有部分是来源于学生学习基础的差异, 还有部分是 来源于学生的学习能力的差异。而在传统的教育教学模 式下, 教师很难对学生进行针对性教学, 而在缺乏针对 性教学的情况下, 学习能力差的学生就很有可能无法吸 收较难的知识, 而学习成绩好的学生在学习较为简单的 知识时，则容易感到浪费时间。计算机辅助教学就能够 帮助教师实现针对性教学, 让不同水平的学生都能够对 知识产生探索欲, 并对知识进行思考, 且具备学习成就 感。

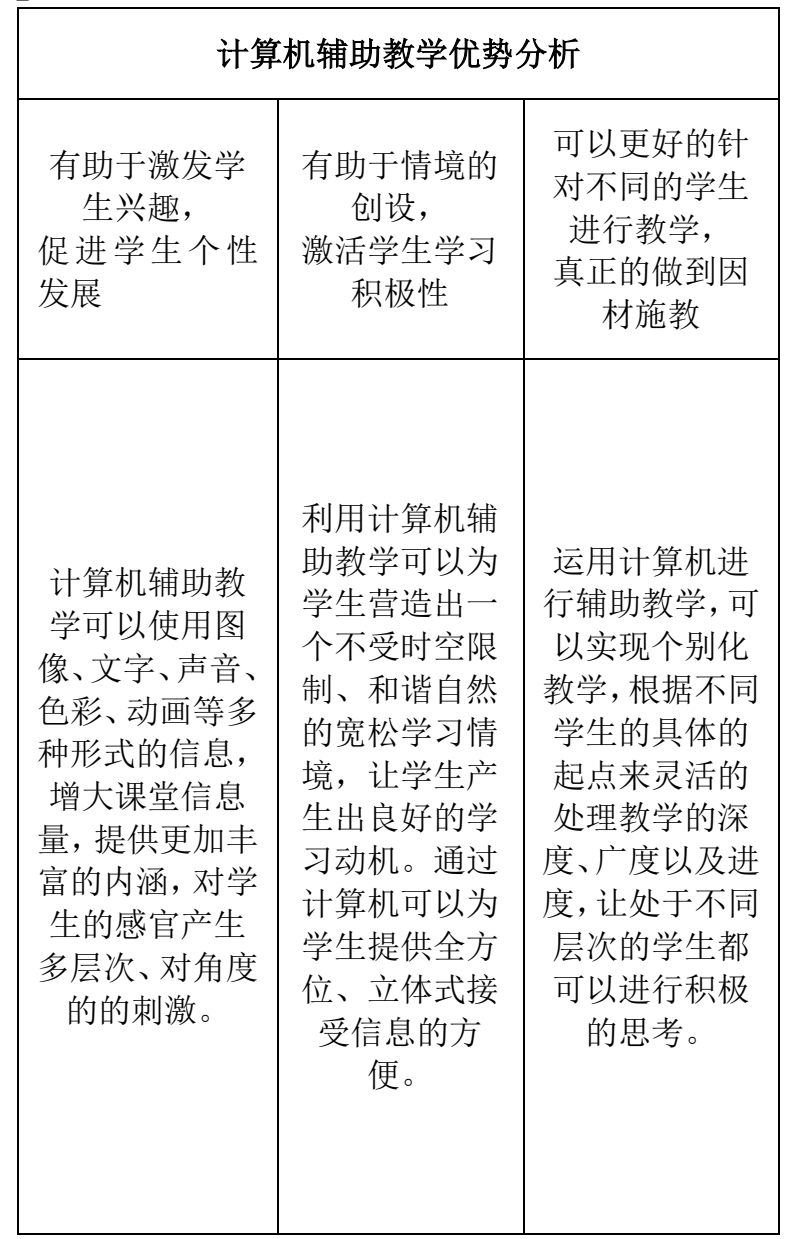

\section{2. 计算机辅助教学中应该注意的问题}

\section{1. 注意对教育观念的改变}

在应试教育背景下, 教师所采取的最多的教学手段 就是传统教育教学手段, 而传统教育教学手段带给学生 的不仅是帮助也有压力, 因为传统教育教学手段限制了 学生思维的发展, 而传统的教育教学观念也遏制了学生
的个性，同时在传统教育教学课堂中，学生的主体地位 并没有得到尊重, 因此有必要运用计算机进行辅助教 学, 在计算机辅助教学中, 教师能够成为教学的引导者, 引导学生学习知识, 并引导学生将知识转化为自己的内 涵，而为了保证教育教学改革的有效性，教师也必须掌 握一定的计算机技术的应用能力，应用计算机技术进行 辅助教学, 保障教学的质量和效率。

\section{2. 不能够过于注重形式忽视了内容，不能 过于注重信息量}

在采用计算机辅助教学手段时, 不能够过于追求形 式, 所谓的过于追求形式也就是指刻意在教学课件中加 入大量的彩色图片, 来吸引学生的注意力。适当的图片 和音频能够使学生将精力投注于学习中, 但是过量的图 片和音频只会分散学生的注意力。因此教师也应该把握 好计算机辅助教学的尺度, 不能让计算机辅助教学成为 教学的弊端。课堂教学的核心和重点永远是知识, 所以 教师需要做的应该是凸显知识, 让学生能够将知识印入 脑海。而不是因为设置过多的图片和音频, 导致学生在 教学结束之后只能记住那些图片和音频, 同时教师还要 注意在教学课件中不能包含太多的信息, 信息太多或是 太繁琐, 都容易使学生记忆混乱, 不利于学生学习, 也 不利于激发学生的学习兴趣。

\section{3. 计算机不能代替教师的作用, 否则会失 去教学的灵活性}

教师在进行教学时不能够将计算机辅助教学手段 当做教学的主体, 学生并不是在跟随计算机技术教学手 段来学习知识, 而是在跟随教师的脚步对知识进行探 索, 教师才是学生学习的引导者, 教师的职责是提升学 生的各方面能力, 发掘学生更多的潜力, 培养学生的思 维, 而不是让学生学会汶览课件。虽然计算机辅助教学 手段能够在教学中起到一定程度的积极作用, 但是滥用 计算机辅助教学手段, 只会使课堂教学情况变得更加复 杂和糟糕。计算机辅助教学手段是无法替代教师的地位 的, 教师应该让计算机辅助教学手段成为自己教育教学 能力的一部分, 并运用这一部分来达成教学目的。

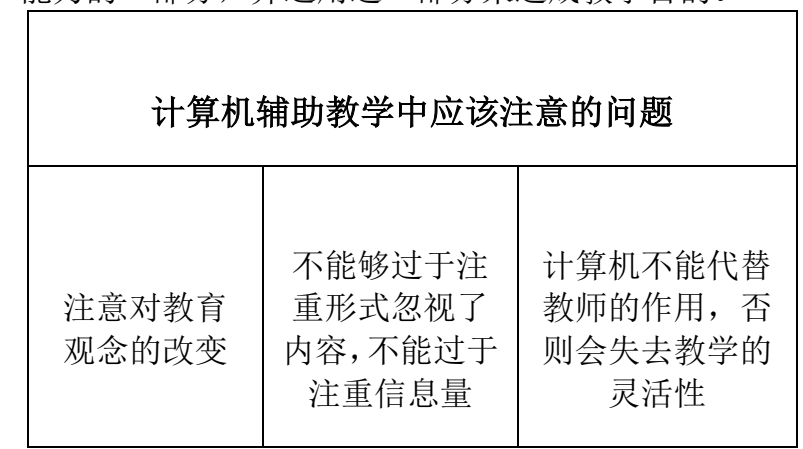




\begin{tabular}{|c|c|c|}
\hline $\begin{array}{c}\text { 在应试教育 } \\
\text { 背景下, 教师 } \\
\text { 所采取的最 } \\
\text { 多的教学手 } \\
\text { 段就是传统 } \\
\text { 教育教学手 } \\
\text { 段, 而传统教 } \\
\text { 育教学手段 } \\
\text { 带给学生的 } \\
\text { 不仅是帮助 } \\
\text { 也有压力, 因 } \\
\text { 为传统教育 } \\
\text { 教学手段限 } \\
\text { 制了学生思 } \\
\text { 维的发展, 而 } \\
\text { 传统的教育 } \\
\text { 教学观念也 } \\
\text { 遏制了学生 } \\
\text { 的个性, 同时 } \\
\text { 在传统教育 } \\
\text { 教学课堂中, } \\
\text { 学生的主体 } \\
\text { 地位并没有 } \\
\text { 得到尊重, 因 } \\
\text { 此有必要运 } \\
\text { 用计算机进 } \\
\text { 行辅助教学。 }\end{array}$ & $\begin{array}{l}\text { 在采用计算机 } \\
\text { 辅助教学手段 } \\
\text { 时, 不能够过于 } \\
\text { 追求形式, 所谓 } \\
\text { 的过于追求形 } \\
\text { 式也就是指刻 } \\
\text { 意在教学课件 } \\
\text { 中加入大量的 } \\
\text { 彩色图片, 来吸 } \\
\text { 引学生的注意 } \\
\text { 力。适当的图片 } \\
\text { 和音频能够使 } \\
\text { 学生将精力投 } \\
\text { 注于学习中, 但 } \\
\text { 是过量的图片 } \\
\text { 和音频只会分 } \\
\text { 散学生的注意 } \\
\text { 力。因此教师也 } \\
\text { 应该把握好计 } \\
\text { 算机辅助教学 } \\
\text { 的尺度, 不能让 } \\
\text { 计算机辅助教 } \\
\text { 学成为教学的 } \\
\text { 弊端。 }\end{array}$ & $\begin{array}{l}\text { 教师在进行教学 } \\
\text { 时不能够将计算 } \\
\text { 机辅助教学手段 } \\
\text { 当做教学的主 } \\
\text { 体, 学生并不是 } \\
\text { 在跟随计算机技 } \\
\text { 术教学手段来学 } \\
\text { 习知识, 而是在 } \\
\text { 跟随教师的脚步 } \\
\text { 对知识进行探 } \\
\text { 索, 教师才是学 } \\
\text { 生学习的引导 } \\
\text { 者, 教师的职责 } \\
\text { 是提升学生的各 } \\
\text { 方面能力, 发掘 } \\
\text { 学生更多的潜 } \\
\text { 力, 培养学生的 } \\
\text { 思维, 而不是让 } \\
\text { 学生学会浏览课 } \\
\text { 件。 }\end{array}$ \\
\hline
\end{tabular}

\section{3. 计算机辅助教学的应用原则分析}

高校利用计算机对大学生进行辅助教学活动相对 于我国传统的教学活动更具有创新力, 但是我国高校想 要将计算机辅助教学引入在教学课堂当中, 帮助大学生 能够更好的进行学习, 必须遵循以下几项应用原则：

第一, 在进行计算机辅助教学过程当中要以学生 为主体性原则。高校利用计算机教学, 它只是高校教师 在教学过程当中的一种辅助性教学手段, 之所以高校会 利用计算机辅助教学, 是为了能够有效的提高学生在课 堂时的学习兴趣, 因此高校教师在课堂中引入计算机辅 助教学时, 必须要以学生为主体进行教学, 而不能使教 学的目的转化为对计算机的学习, 从而忽视了学生的综 合学习需求。课堂教学只是教师在教学过程当中, 需要 去引导学生能够自主的学习, 而不是一味的给学生灌输 学习的知识内容, 对教学的主要目的就是为了培养、锻 炼学生的学习思考能力, 而高校课程引入计算机辅助教 学也是为了能够锻炼学生的实践能力以及思维能力。

第二，第二，教师在课堂当中引入计算机辅助教 学, 要注重学生与计算机的交互性原则。由于计算机只 是一台机器, 因此, 学生在对计算机辅助学习过程当中,
会时常感到枯燥乏味, 所以教师在进行计算机辅助教学 时, 应该要加强学生与计算机之间的互动性, 使学生在 进行计算机辅助教学过程中更加有趣兴, 同时也能够提 高学生对计算机学习的实践能力。

第三, 实效性原则。计算机辅助教学只是一种辅助 性的手段教学, 而老师在课堂当中引入计算机辅助教学 时还是要以教师教学为主体, 教师在教学的过程当中, 要合理的利用计算机辅助教学手段来提高学生的学习 效率为目标, 帮助学生能够真正学习到更多的知识。

\section{4. 计算机辅助教学的应用策略分析}

教师在课堂当中引入计算机辅助教学时应该要注 意以下策略：

\section{1. 明确教学目标}

高校教师想要将计算机辅助教学引入到课程当中, 首先要明确教学目标, 并且高校教师在课堂教学之前要 进行课件计划。并且教师在进行课件设计时, 要制定明 确的教学目标, 并根据合理的教学目标将计算机辅助教 学引入课件当中来帮助学生能够更好的学习。另外, 教 师在引入计算机辅助教学课件设计时, 要对计算机辅助 教学的概念内都要有一定的了解, 并且在课堂当中也可 以通过制定一些图片、视频来帮助学生能够更好的了理 解计算机辅助学习。教师在课堂当中对于引进计算机辅 助教学的目标主要是为了通过充分发挥计算机教学功 能, 来全面提高学生学习的效率性。

\section{2. 提高学生的学习兴趣}

在生活当中, 人们对于一件事物的学习通常首先是 有没有兴趣, 然而学生的学习也是如此。因此教师在课 堂当中引进计算机辅助进行教学, 要特别注重大学生对 于计算机的学习兴趣。因为当学生对计算机产生了学习 兴趣, 才能够使学生能够自主的学习; 而如果学生对于 计算机并不感兴趣, 就会导致学生在学习过程中经常感 到枯燥乏味, 从而对这类学习毫无兴趣。

\section{3. 不断的对计算机辅助教学活动进行创新}

教师在对学生进行计算机辅助教学时, 不能只是一 味地对学生灌输计算机相关知识, 而是要通过教学引导 学生去自主的学习, 从而激发学生对于学习的强烈兴 趣。因此教师在进行计算机辅助教学课程当中, 要对计 算机技术不断的创新, 激发大学生的好奇心, 提高大学 生对于计算机的学习能力。 


\section{5. 结语}

综上所述, 计算机辅助教学手段在教学中的应用是 具备一定的优势的, 但是也存在一定的问题, 而想要避 免该问题的产生, 就要看教师对计算机辅助教学手段应

用情况, 如果教师能够合理的运用计算机辅助教学 手段进行教学, 那么就能够充分发挥出计算机辅助教学 手段的作用, 提升教学效率, 保障教学质量, 但是如果 教师过度使用计算机辅助教学手段, 就会对教学产生更 加不利的影响。

\section{REFERENCES}

[1] The Construction of Network-Based Computer-Aided Teaching Platform -- Taking the Xingcheng Municipal Party School as an example [J]. Information recording material. 2019(05)

[2] The practical application of computer aided teaching in geography curriculum education in colleges and universities $[\mathrm{J}]$. Guifeng. Computer knowledge and technology. 2019(23)

[3] On the Role and Application of Computer-Aided Teaching in History Teaching [J]. Zhao Xuemei. Information technology education in China. 2014(12)

[4] The current practice and thinking of computer aided teaching [J]. The way to success. 2016(36)

[5] Application of computer aided teaching in optical teaching [J]. Li Guocai. Middle school physics teaching reference. 2017(08)

[6] A Study on the Role of Computer-Aided Teaching in Audio-visual Education [J]. Curriculum education research. 2017(11) 